\title{
Optimal zwitterionic surfactant slug for an improved oil recovery in oil- wet carbonate rocks
}

\author{
Madison Barth ${ }^{1}$, Japan Trivedi ${ }^{1}$, Benedicta Nwani ${ }^{1}$, Yosamin Esanullah ${ }^{1}$ \\ ${ }^{1}$ Department of Civil and Environmental Engineering, University of Alberta
}

\begin{abstract}
Of recent, there has been research and development in the technologies/techniques required to meet the ever-growing energy demand in the world. Oil is a major source of energy which is contained in over $50 \%$ of carbonate reservoirs. The oil/mixed wettability of carbonate rocks makes it technically challenging to recover the needed oil. The process of crude oil recovery has three different stages primary, secondary and tertiary recovery. Tertiary recovery is also known as enhanced oil recovery or EOR. EOR includes the use of surfactants to reduce the interfacial tension between a hydrocarbon and brine, thus suspending them both in a microemulsion. Surfactant performance can be affected by multiple variables, including brine salinity, surfactant concentration, and type of hydrocarbon. A petroleum engineer must take all variables into consideration when selecting a surfactant to make sure that its efficiency is as high as possible, especially because the use of surfactants is costly.

In this work, a chembetaine zwitter ionic surfactant of two different concentrations are evaluated at various synthetic formation brine salinities for their favourable wettability alteration and interfacial tension reduction in oil-wet carbonate- Silurian Dolomite. For the evaluation, fluid-fluid and rock-fluid analysis are carried out to select the optimal surfactant concentration and brine salinity with the greatest improved oil recovery potential.

Results are indicative that the surfactant at the two concentrations studied is compatible at the ranges of salinities evaluated. However, from the fluid-fluid analysis, there was no ultra-low interfacial tension that is needed for oil mobilization. More so, the rock-fluid analysis shows that the surfactant is not able to alter the wettability of oil-wet rocks favourably. The optimal surfactant slug for the greatest oil recovery, in this case, would be expected at $0.5 \%$ surfactant concentration in 10,000 ppm synthetic formation brine salinity. This study, therefore, serves as a guide for the design of optimal surfactant slug in oil-wet carbonate cores requires to reduce non-productive time, prevent reservoir damage and therefore improve recovery.
\end{abstract}

Key words:

surfactant, zwitterionic, enhanced oil recovery, oil -wet, silurian dolomite

Cite as: Barth M., Trived J., Nwani B., Esanullah Y. 2019. Optimal zwitterionic surfactant slug for an improved oil recovery in oil-wet carbonate rocks. Alberta Academic Review, Vol 2 (2) 7-8, WISEST Special Issue (not peer-reviewed), DOI: 10.29173/aar45.

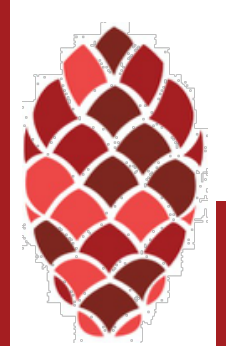


Barth et al., 2019

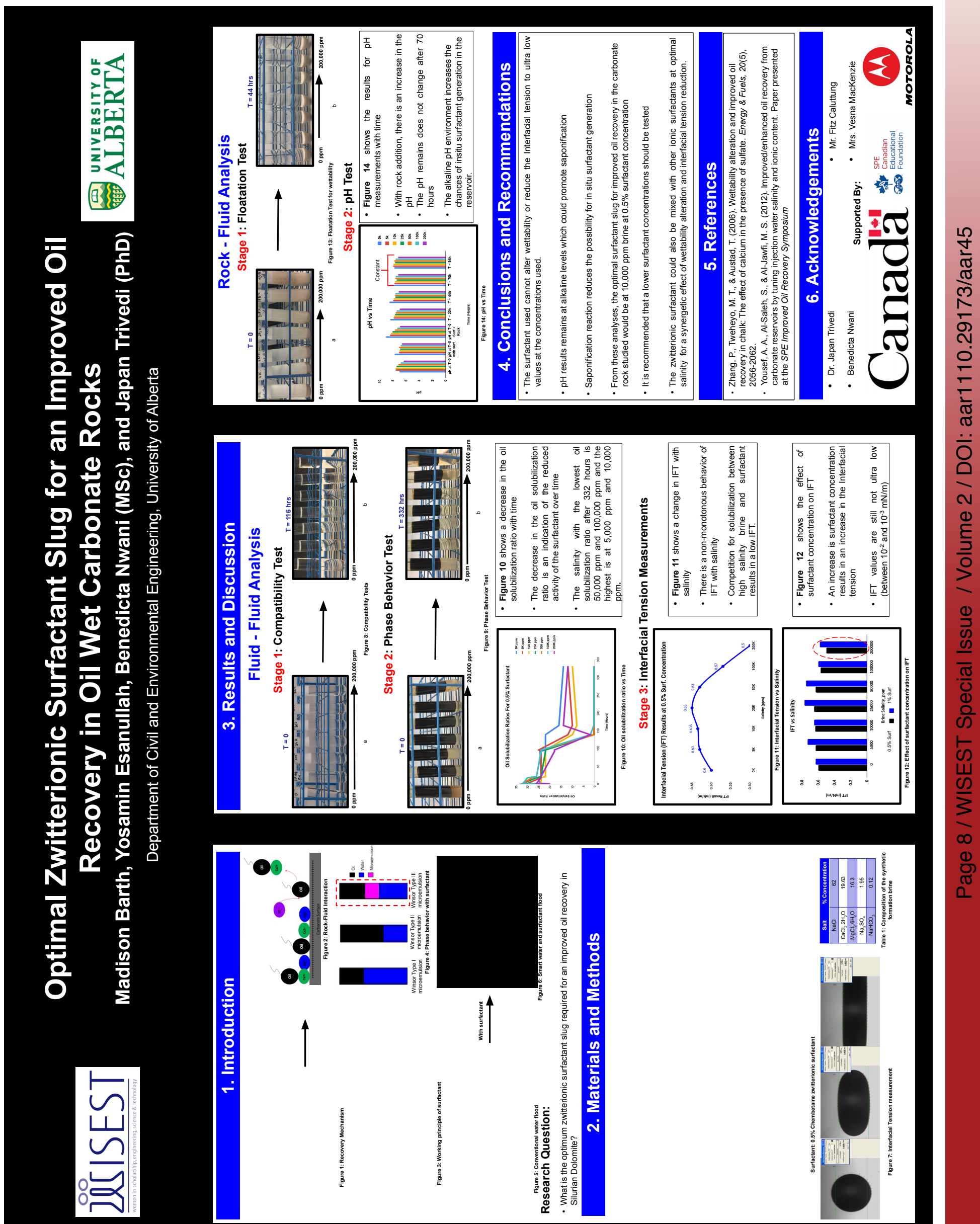

